\title{
Exploring REACH as a potential data source for characterizing ecotoxicity in life cycle assessment
}

Müller, Nienke; de Zwart, Dick; Hauschild, Michael Zwicky; Kijko, Gaël; Fantke, Peter

\section{Published in:}

Environmental Toxicology and Chemistry

Link to article, DOI:

10.1002/etc. 3542

Publication date:

2017

Document Version

Peer reviewed version

Link back to DTU Orbit

Citation (APA):

Müller, N., de Żwart, D., Hauschild, M. Z., Kijko, G., \& Fantke, P. (2017). Exploring REACH as a potential data source for characterizing ecotoxicity in life cycle assessment. Environmental Toxicology and Chemistry, 36(2), 492-500. https://doi.org/10.1002/etc.3542

\section{General rights}

Copyright and moral rights for the publications made accessible in the public portal are retained by the authors and/or other copyright owners and it is a condition of accessing publications that users recognise and abide by the legal requirements associated with these rights.

- Users may download and print one copy of any publication from the public portal for the purpose of private study or research.

- You may not further distribute the material or use it for any profit-making activity or commercial gain

- You may freely distribute the URL identifying the publication in the public portal 
Müller, N., de Zwart, D., Hauschild, M., Kijko, G., \& Fantke, P., 2016. Exploring reach as potential data source for characterizing ecotoxicity in life cycle assessment. Environmental Toxicology and Chemistry, 9999(9999), pp.1-9. DOI: 10.1002/etc.3542.

\section{Exploring REACH as potential data source for characterizing ecotoxicity in}

\section{2 life cycle assessment}

3 Nienke Müller†, Dick de Zwartł, Michael Hauschild†, Gaël Kijko ${ }^{\S}$, Peter Fantke*†

4

5 tDepartment of Management Engineering, Technical University of Denmark, Kgs. Lyngby,

6 Denmark

$7 \quad \ddagger$ National Institute for Public Health and the Environment (RIVM), Bilthoven, Netherlands

$8 \quad{ }^{\S}$ École Polytechnique de Montréal, Montreal, QC, Canada

9

10 *Corresponding author: Tel.: +45 45254452, fax: +45 45933435. E-mail: pefan@ dtu.dk 


\section{Abstract}

Toxicity models in life cycle impact assessment (LCIA) currently only characterize a small fraction of marketed substances. This is mainly due to limitations in the underlying ecotoxicity data. One approach to improve the current data situation in LCIA is to explore new data sources, such as the European database of the Registration, Evaluation, Authorisation and Restriction of Chemicals (REACH). We explored REACH as potential data source for LCIA based on matching reported ecotoxicity data for substances that are currently also included in the UNEP/SETAC scientific consensus model USEtox for characterizing human toxicity and ecotoxicity impacts in LCIA. Data are evaluated with respect to number of data points, reported reliability and test duration, and are compared with data listed in USEtox at the level of hazardous concentrations per substance. Our results emphasize deviations between data available in REACH and USEtox. The comparison of ecotoxicity data in REACH and USEtox shows the general potential of REACH ecotoxicity data to be used in LCIA toxicity characterization, but also highlights issues related to compliance with $\mathrm{REACH}$ reporting requirements and different assumptions underlying $\mathrm{REACH}$ as regulatory risk assessment support database and LCIA. We recommend to systematically investigate current quality-, extrapolation-, and applicability-related issues, before considering REACH as data source for use in LCIA and to also look at additionally available databases, published studies and reports. 
More than 100,000 substances are awaiting evaluation in the European Union (EU) for their safe use in various technological products and systems [1]. Life cycle assessment (LCA) is widely applied as a methodology to quantitatively compare the overall environmental performance of products and systems over their full life cycle looking at various impacts related to chemical emissions and resource use [2]. To ensure comparability across impact categories, average or representative values are used in the life cycle impact assessment (LCIA) phase of LCA as "best estimates" to characterize potential impacts on humans and ecosystems associated with chemical emissions occurring over a product life cycle [3]. Aquatic ecotoxicity is one of the impact categories in LCIA with high associated variability in characterization results and limitations mainly related to data availability and extrapolation from acute to chronic effects. Several tools have been developed over the last 2 decades to characterize and compare aquatic ecotoxicity impacts of chemical emissions in LCA, but all rely on different assessment models, assumptions, and data, which is one of the main reasons for high variability and inconsistency in assessment results across tools [4]. Variability across tools has been addressed in a multi-year consensus building effort to harmonize existing models under the auspices of the United Nations Environment Programme (UNEP)/Society of Environmental Toxicology and Chemistry (SETAC) Life Cycle Initiative. This effort resulted in the development of the scientific consensus model USEtox for characterizing human toxicity and freshwater ecotoxicity impacts of chemical emissions for use in LCA and other comparative assessments [5]. The consensus building process is described elsewhere [6, 7]. However, variability and uncertainty related to underlying aquatic ecotoxicity data in USEtox and other LCIA models as well as low substance coverage compared to marketed and potentially harmful chemicals remain critical issues that need to be addressed to improve ecotoxicity characterization in LCA. 
Müller, N., de Zwart, D., Hauschild, M., Kijko, G., \& Fantke, P., 2016. Exploring reach as potential data source for characterizing ecotoxicity in life cycle assessment. Environmental Toxicology and Chemistry, 9999(9999), pp.1-9. DOI: 10.1002/etc.3542.

The starting point for characterizing ecotoxicological effects in LCA is the chemical concentration in freshwater at which $50 \%$ of the tested aquatic organisms are affected, EC50. EC50 for organic substances in USEtox are currently taken from 2 scrutinized and qualityassured data sources as part of the consensus-building process [5]. One source is based on data from the RIVM's E-toxBase [8], while the other source is mainly based on data from ECOTOX [9] and IULCID [10]. Preference is given to chronic data [5] as long as they represent measured EC50 values. If chronic data are not available, acute data are used applying a fixed acute-to chronic extrapolation ratio (ACR) of 2 [11]. Extrapolating from acute to chronic data certainly requires additional research, but is not further discussed in the present study. Freshwater ecotoxicity effect factors based on EC50 are available in USEtox for approximately 2500 substances, while other LCIA characterization models typically provide ecotoxicity effect factors for less than 1000 substances [12]. Hence, most commercially used chemicals remain to be characterized, mainly due to the limited availability or use of underlying EC50 data. More specifically, reported chronic EC50 values are in general relatively rare and the lack of data and the increased uncertainty by extrapolating from acute data constitute unsolved issues for a reliable ecotoxicity characterization in LCIA [13]. Thus, exploring new sources for freshwater ecotoxicity data for use in LCIA is required to improve current ecotoxicity characterization. One potential source for ecotoxicity information is the database of the Registration, Evaluation, Authorisation and Restriction of Chemicals (REACH) established by the European Chemicals Agency (ECHA) under Regulation (EC) No 1907/2006 that became effective in June 2007 in consequence of the new EU chemicals legislation [14]. Very few studies already considered REACH as potential data source for use in LCIA. Askham (2012) [15] compared ecotoxicity data from REACH registration dossiers with data used in USEtox for benzene and found that REACH provides more data than are currently used in USEtox and that REACH may be useful to fill existing data gaps. The study by 
Müller, N., de Zwart, D., Hauschild, M., Kijko, G., \& Fantke, P., 2016. Exploring reach as potential data source for characterizing ecotoxicity in life cycle assessment. Environmental Toxicology and Chemistry, 9999(9999), pp.1-9. DOI: 10.1002/etc.3542.

Askham recommended using REACH and USEtox exploiting concurrence and synergies to identify potential conflicts, while a qualitative assessment of the REACH data, i.e. the evaluation of the data with respect to their reliability and quality for inclusion into the scientific consensus model USEtox was not performed. Igos et al. (2014) [16] developed characterization factors using REACH ecotoxicological data for 9 dishwasher detergents, which are currently not characterized in USEtox. Despite general agreement with results from other studies, Igos and coauthors doubt the reliability of the underlying REACH data, since underlying data requirements were not completely met or testing studies were poorly documented. As a result, further investigation of the qualitative assessment of REACH data was recommended. A systematic analysis of appropriateness and applicability of REACH data for use in LCIA toxicity models is, however, still missing. In response to this need, we investigate in the present study the agreement between aquatic ecotoxicological data submitted under REACH and data used in the life cycle toxicity assessment model USEtox. The main aim is thereby to identify the potential for improving LCIA toxicity characterization by incorporating REACH effect data and related feasibility requirements. To address this aim, we focus on 4 objectives: (i) to identify a set of chemicals that are on the one hand registered under REACH and on the other hand included in USEtox; (ii) to analyze for these chemicals the aquatic ecotoxicity information reported in $\mathrm{REACH}$ with respect to their variability and stated data reporting quality; (iii) to calculate the average toxicity for each chemical from REACH data and compare it with the average toxicity currently used in USEtox; and (iv) discuss options and provide preliminary recommendations for improving aquatic ecotoxicity assessment in LCA based on REACH.

\section{MATERIALS AND METHODS}

The main steps involved in selecting, preprocessing, and analyzing freshwater ecotoxicity data are shown in Figure 1. 

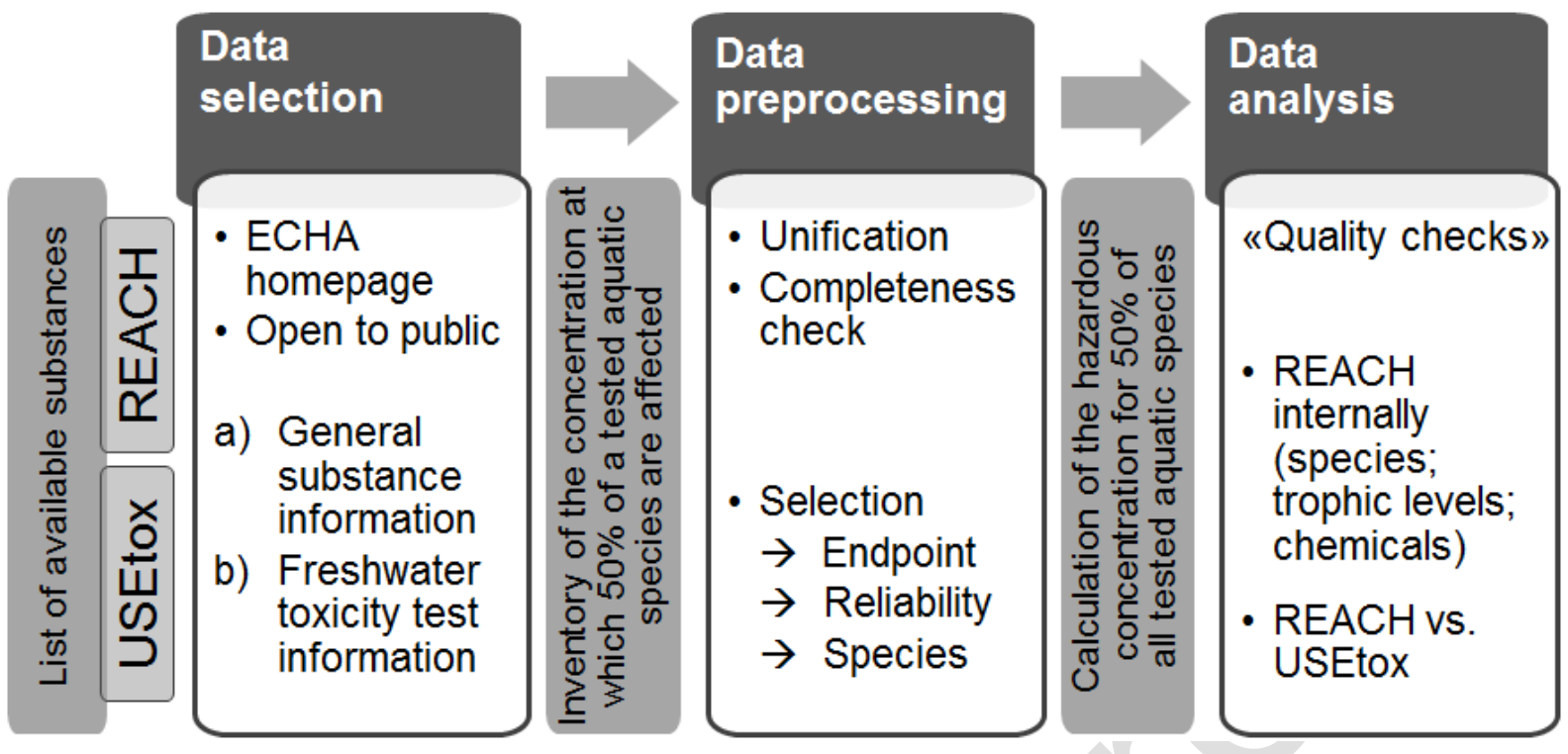

114 Figure 1. Main steps involved in REACH freshwater ecotoxicity data selection,

115 preprocessing, and analysis for potential use in life cycle toxicity characterization models

Data selection

For comparing freshwater ecotoxicity data available in REACH with data currently

119 used in LCIA characterization models, the starting point is to look at those substances for

120 which a submitted dossier under REACH is available and which are also included in USEtox.

121 We hence compiled a database containing all individual aquatic ecotoxicological effect data

122 reported under REACH for the full set of substances for which also ecotoxicity effect factors exist in USEtox. Relevant information for tested substances is taken from REACH

124 registration dossiers which have been assigned a registration number and are accessible on the

125 ECHA homepage (echa.europa.eu/information-on-chemicals/registered-substances). All

126 information collected from REACH is provided in the present study (Supplemental Data,

127 Table S1) and was systematically included to identify and evaluate data for different

128 substances and to assess data source, toxicity testing method and resulting ecotoxicity data.

129 The information used for EC50 data evaluation includes for the substance identification the 
130 CAS registration number and the IUPAC name. Study result type, reliability score, tested

131 species, exposure duration, endpoint type, and effect concentration are included as aquatic

132 toxicity test information.

Data preprocessing

Extracted data for the selected substances were harmonized and scrutinized in a preprocessing step to prepare a consistent inventory set of EC50 values based on REACH. Preprocessing included harmonization of differently spelled test species names, reported exposure duration units (e.g. converting $48 \mathrm{~h}$ into $2 \mathrm{~d}$ ) and effect concentration units (e.g. converting $1 \mathrm{~g} / \mathrm{L}$ into $1000 \mathrm{mg} / \mathrm{L}$ or removing data points with ambiguous units like ppm that

140 can be based on mass or molarity, which is typically not indicated). Furthermore, effect

141 concentration endpoints other than EC50 or equivalent endpoints IC50 (inhibitory concentration) and LC50 (lethal concentration) were removed from the data set. EC50, LC50, and IC50 were selected as endpoints, because EC50 values are mostly from acute tests, where

144 the endpoint is usually lethality (LC50) or in the case of Daphnia immobilization (IC50).

145 Finally, data were removed for test species 'activated sludge' and data that were not measured

146 but estimated (e.g. study result type 'read-across data', 'QSAR', or 'estimated by

147 calculation'), and data entries were then checked for completeness of test details necessary to

148 subsequently calculate substance-specific average toxicity including reliability score, test

149 organism (species), test category assigned by ECHA containing the tested trophic level,

150 exposure duration, and type of endpoint. As the information requirements for ecotoxicological

151 data in REACH depend on the chemical tonnage, either referring to produced or imported

152 substance volume (Table 1) [14], more data are typically available for substances with higher 153 production or import volumes. 
155 Table 1. Aquatic ecotoxicological information required for substance registration under

156 REACH depending on the annual quantity manufactured or imported according to Annexes

157 VII to X of Regulation (EC) No 1907/2006 [14]

\begin{tabular}{lcccc}
\hline Aquatic Ecotoxicological Information* & $\begin{array}{c}\geq 1 \mathrm{t} / \mathrm{yr} \\
\text { Annex VII }\end{array}$ & $\begin{array}{c}\geq 10 \mathrm{t} / \mathrm{yr} \\
\text { Annex VIII }\end{array}$ & $\begin{array}{c}\geq 100 \mathrm{t} / \mathrm{yr} \\
\text { Annex IV }\end{array}$ & $\begin{array}{c}\geq 1000 \text { t/yr } \\
\text { Annex X }\end{array}$ \\
\hline $\begin{array}{l}\text { Short-term toxicity testing on invertebrates } \\
\text { (preferred species Daphnia) }\end{array}$ & $\mathrm{X}$ & $\mathrm{X}$ & $\mathrm{X}$ & $\mathrm{X}$ \\
$\begin{array}{l}\text { Growth inhibition study aquatic plants } \\
\text { (algae preferred) }\end{array}$ & $\mathrm{X}$ & $\mathrm{X}$ & $\mathrm{X}$ & $\mathrm{X}$ \\
$\begin{array}{l}\text { Short-term toxicity testing on fish } \\
\text { (long-term toxicity testing instead of short-term } \\
\text { may be considered) }\end{array}$ & $\mathrm{X}$ & $\mathrm{X}$ & $\mathrm{X}$ \\
$\begin{array}{l}\text { Activated sludge respiration inhibition testing } \\
\text { Long-term toxicity testing on invertebrates } \\
\text { (preferred species Daphnia) }\end{array}$ & $\mathrm{X}$ & $\mathrm{X}$ & $\mathrm{X}$ \\
\begin{tabular}{l} 
Long-term toxicity testing on fish \\
\hline
\end{tabular} & & $\mathrm{X}$ & $\mathrm{X}$ \\
\hline
\end{tabular}

*Except for the long-term testing, the studies do not need to be conducted if there are factors indicating that aquatic toxicity is unlikely to occur. This could for instance be the case for substances that have a high insolubility in water or are unlikely to cross biological membranes. In this case long-term testing is advised, but not compulsory allows the experimental study information to be ranked and organized for focusing on the most relevant data for toxicity assessment [18]. Main focus of this scoring system is on the data reporting requirements, especially regarding the use of standard test guidelines and

167 within the REACH registration process, each registrant submitting data needs to assign the 168 appropriate score [19]. Through an evaluation process ECHA checks the compliance with reporting requirements of at least $5 \%$ of the registration dossiers received for each tonnage

171 without restriction') and 2 ('reliable with restrictions') are used, whereas all other (i.e.

172 considered non-reliable) data points were ignored. 
Müller, N., de Zwart, D., Hauschild, M., Kijko, G., \& Fantke, P., 2016. Exploring reach as potential data source for characterizing ecotoxicity in life cycle assessment. Environmental Toxicology and Chemistry, 9999(9999), pp.1-9. DOI: 10.1002/etc.3542.

\section{Data analysis}

Freshwater aquatic ecotoxicity effect factors, applied in the calculation of freshwater ecotoxicity characterization factors, are defined in USEtox as the change in the potentially affected fraction (PAF) of exposed freshwater species per change in concentration of truly dissolved chemical in freshwater. The chosen working point on the PAF curve corresponds to a $50 \%$ fraction of species that is potentially affected [12] and is referred to as hazardous concentration, HC50 (mg/L), at which $50 \%$ of exposed aquatic ecosystem species are showing effects above their species-specific EC50 (mg/L). In the USEtox substance data files chemical-specific HC50 are available in log scale. Hence, to compare and assess ecotoxicity data provided in REACH directly with data reported in USEtox, the HC50 for a chemical has to be calculated in 5 steps from the selected REACH EC50 data. First, a set of ecotoxicological effect data $\mathrm{EC} 50_{i, j} \triangleq\left\{\mathrm{EC} 50_{i, j}^{\mathrm{REACH}}, \mathrm{IC} 50_{i, j}^{\mathrm{REACH}}, \mathrm{LC} 50_{i, j}^{\mathrm{REACH}}\right\}$, is built composed of all reported species-specific data points $i$ for all aquatic test species $j$ per substance from the full list of extracted REACH data including effect (EC50), inhibitory (IC50) and lethal (LC50) concentration endpoints. Second, data are structured into chronic or acute exposure duration by means of a taxonomy data set (Supplemental Data, Table S2). In case the test species were not stated or are not available in the taxonomy, test durations were extrapolated based on stated trophic level and acute test durations for different trophic levels ( $\leq 1 \mathrm{~d}$ for microorganisms, $\leq 4 \mathrm{~d}$ for algae, cyanobacteria and crustaceans, and $\leq 7 \mathrm{~d}$ for invertebrates, fishes and aquatic plants other than algae) [20] based on various sources [11, $21,22]$ and additional expert judgement. Third, all data points with assigned 'acute' exposure duration are used to estimate the preferred 'chronic' data by applying an acute-to-chronic ratio (ACR) of 2 in line with the generic ACR applied in USEtox [12]. With this, the effect data are restructured as $\mathrm{EC} 50_{i, j} \triangleq\left\{\mathrm{EC} 50_{i, j}^{\text {chronic }}, \mathrm{EC} 50_{i, j}^{\text {acute }} / \mathrm{ACR}\right\}$. Although ACR may vary considerably between chemicals and test species as shown for selected cationic metals [23], 
Müller, N., de Zwart, D., Hauschild, M., Kijko, G., \& Fantke, P., 2016. Exploring reach as potential data source for characterizing ecotoxicity in life cycle assessment. Environmental Toxicology and Chemistry, 9999(9999), pp.1-9. DOI: 10.1002/etc.3542.

we apply the generic ACR of USEtox for consistency, thereby acknowledging that further research is required to refine this assumption in future exercises. Fourth, an average value is calculated across all data points per test species in log scale, building a set of species-specific $\log \mathrm{EC}_{50}$ for each chemical. Fifth, the average of all $\log \mathrm{EC} 50_{j}$ per chemical is calculated and denoted as $\log \mathrm{HC} 50$ - this metric finally matches the log of the hazardous concentration for $50 \%$ of the included test species that is reported in USEtox substances data files. The last 2 steps are performed separately for the data set of reported chronic data alone and for the combined set of reported chronic data and chronic data converted from reported acute data, where the latter set is referred to as 'combined acute and chronic' for simplicity.

\section{RESULTS \\ Selected freshwater ecotoxicity data from REACH \\ REACH includes ecotoxicity information from more than 50000 dossiers for}

approximately 15000 registered substances in total, of which more than 9000 registered with a CAS number. Around $75 \%$ of the substances without CAS number are registered as

Notification of New Substances (NONS) that will be updated gradually by ECHA [24]. The remaining substances without a CAS number are incompletely registered or mixtures, reaction products, distillate fractions, etc. Out of substances with CAS, approximately 7500 unique chemicals are represented with the rest being multiple registrations per substance having different registration or submission types. USEtox 2.0 provides ecotoxicity data for 2498 out of 3076 organic substances and for all of the 27 included cationic metals. Matching REACH with USEtox for registered substances for which log HC50 can be determined based on the REACH data yields a list of 819 unique chemicals that are included in our data set. For these chemicals, a total of 22834 individual ecotoxicity data points was found in REACH as of April 2015. The distribution of the data on different reliability scores and types of ecotoxicity endpoints is summarized for the 819 selected substances in Table 2. 
Table 2. Statistics on the distribution across reliability scores and ecotoxicity endpoints of the

227 REACH data for 819 selected substances. Numbers highlighted in grey are data points

228 considered for further analysis in the present study

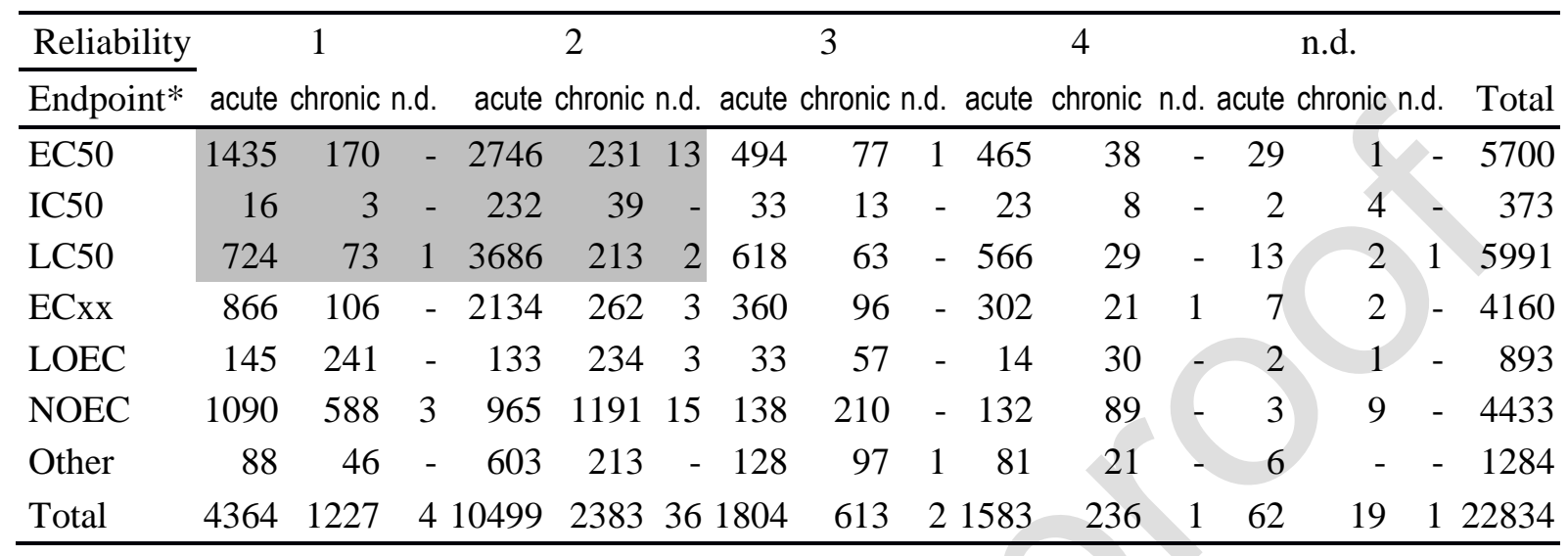

*EC50: Effect Concentration (50\% of test organisms affected); IC50: Inhibitory

230 Concentration (50\% of test organisms affected); LC50: Lethal Concentration (50\% of test

231 organisms affected); ECxx: Effect Concentration (xx\% of test organisms affected); LOEC:

232 Lowest Observed Effect Concentration; NOEC: No Observed Effect Concentration. as starting point for our data analysis corresponding to EC50, IC50 or LC50 (the endpoints

236 prescribed and used for calculation of effect factors in USEtox) with reliability 1 or 2

237 (highlighted data in Table 2). Preprocessing (harmonizing and scrutinizing) these data finally 238 yielded a data set of 787 unique substances with 7723 measured ecotoxicity data points, of 239 which $7.4 \%$ are based on chronic and $92.6 \%$ on acute tests. In our final data set, the number 240 of data points per substance varies between 1 (e.g. 2,5-dichloroaniline, CAS: 95-82-9 or 2,5241 dimethylphenol, CAS: 95-87-4) and 171 (silver, CAS: 7440-22-4) with an average of 9.8 data 242 points per substance. Many substances with only few data points remaining in our final data 243 set have more reported data in $\mathrm{REACH}$, but these did not pass our selection criteria (i.e. not 244 considered reliable in REACH or endpoints currently not included in USEtox). The average 
Müller, N., de Zwart, D., Hauschild, M., Kijko, G., \& Fantke, P., 2016. Exploring reach as potential data source for characterizing ecotoxicity in life cycle assessment. Environmental Toxicology and Chemistry, 9999(9999), pp.1-9. DOI: 10.1002/etc.3542.

245 number of data points per substance for chronic tests is 0.72 and data covering 3 trophic

246 levels are reported on average per substance (data not shown).

REACH ecotoxicity data analysis

Our final set of scrutinized REACH ecotoxicity data is analyzed (i) at the level of

species-specific $\log \mathrm{EC} 50_{j}$ values that are compared with regard to different test durations

251 (assigned 'chronic' vs. assigned 'acute') and reliability scores (reported reliability 1 vs. 2),

252 and (ii) at the level of species-specific chronic $\log \mathrm{EC} 50_{j}$ values that are compared with regard

253 to different trophic levels.

(i) Influence of test duration and reliability score is investigated plotting species-

256 specific acute $\log \mathrm{EC} 50_{j}$ values against chronic $\log \mathrm{EC} 50_{j}$ values per substance (average per

257 substance across all species-specific 'acute' respectively chronic, 'reliability 1' and 'reliability

2582 ' EC50 data points) for 251 different combinations of substance and species (Figure 2A) and

259 plotting REACH reliability score 1 versus reliability score $2 \log \mathrm{EC}_{50} 0_{j}$ values (chronic and

260 acute) for 252 different combinations of substance and species (Figure 2B). 


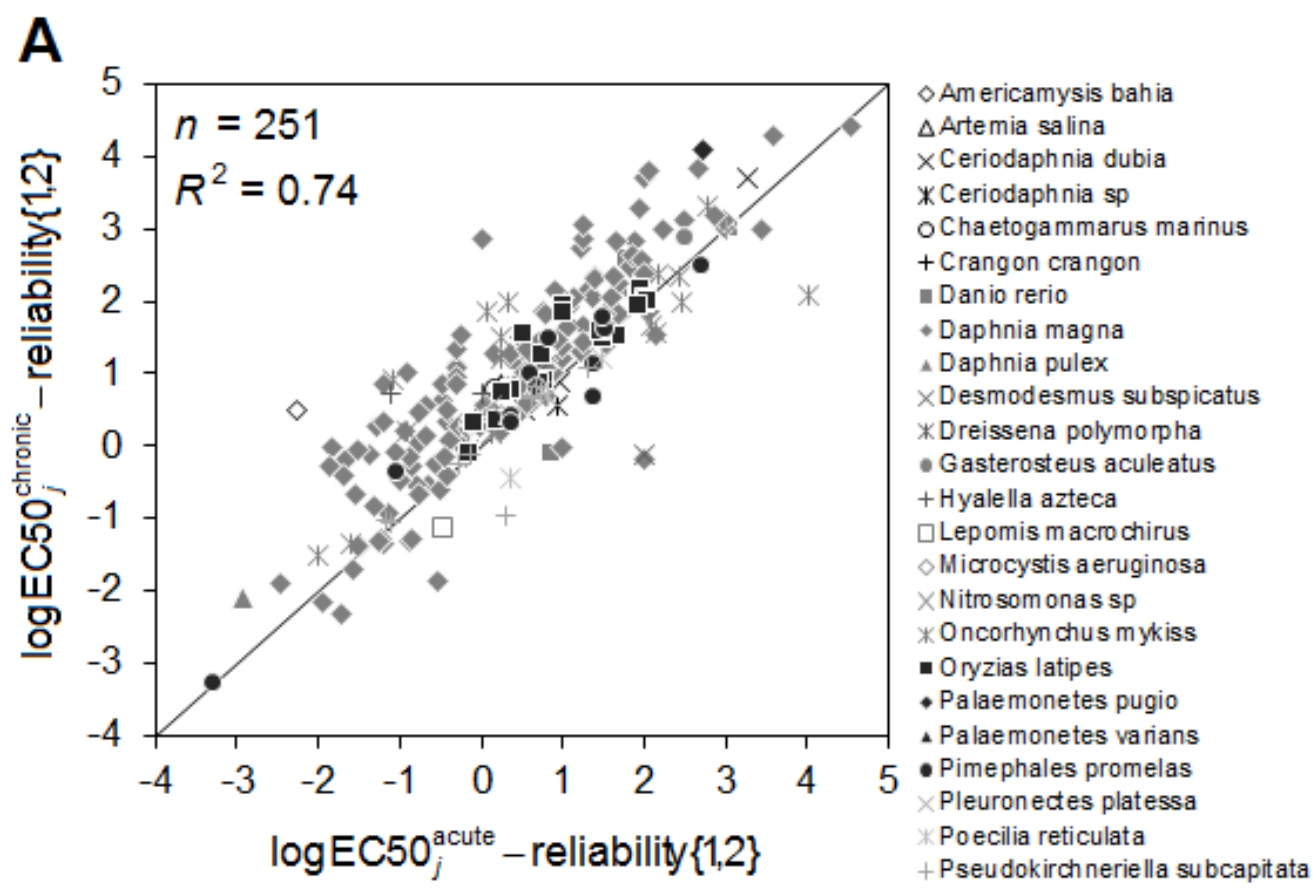

B

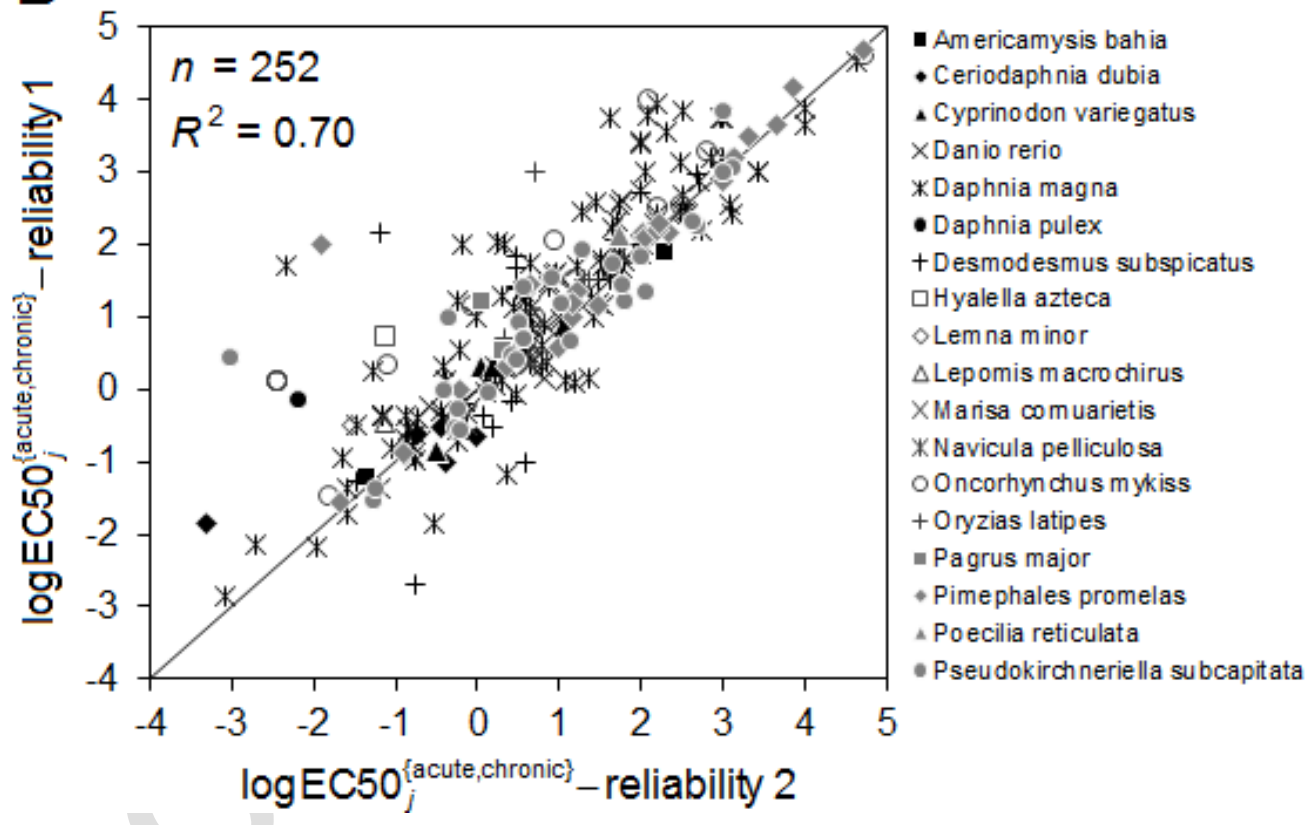

Figure 2. Comparing $\log \mathrm{EC}_{50}$ values for $(\mathbf{A})$ chronic vs. acute data with reliability scores 1 and 2, and for $(\mathbf{B})$ acute and chronic data with reliability score 1 vs. reliability score 2. All axes are on a $\log _{10}$ scale. Diagonal solid line indicates the hypothetically ideal 1:1 confirmation relationship between data on $\mathrm{y}$-axis and $\mathrm{x}$-axis

For comparing test durations, data with reported reliabilities 1 and 2 were combined, while for comparing reliability scores, acute and chronic data were combined to maximize the 
Müller, N., de Zwart, D., Hauschild, M., Kijko, G., \& Fantke, P., 2016. Exploring reach as potential data source for characterizing ecotoxicity in life cycle assessment. Environmental Toxicology and Chemistry, 9999(9999), pp.1-9. DOI: 10.1002/etc.3542.

number of data points that can be considered. Chronic and acute $\log \mathrm{EC}_{5} 0_{j}$ values in Figure 2A generally fall in the same range with an average deviation of a factor 2.9 (calculated from an average difference of $0.46 \log$ units) and with $90 \%$ of chronic versus acute $\log \mathrm{EC} 0_{j}$ values falling within a difference of a factor 23 (1.37 log units). Some species, however, show differences in chronic versus acute $\log \mathrm{EC}_{5} 0_{j}$ values that vary up to more than 2 orders of magnitude, such as chronic versus acute $\log \mathrm{EC} 50_{j}$ for Americamysis bahia varying by up to a factor 613 (2.8 log units) after exposure to zinc pyrithione (CAS: $13463-41-7)$ and log EC50 of Daphnia magna varying by up to a factor 159 (2.2 log units) after exposure to isopropyl myristate (CAS: 110-27-0). A similar picture is obtained when comparing combined acute and chronic $\log \mathrm{EC}_{50}$ data with reported reliability score 1 versus data with reported reliability score 2 . Good agreement is shown between most combined $\log \mathrm{EC} 50_{j}$ data with reliability score 1 versus combined $\log \mathrm{EC} 50_{j}$ data with reliability 2 . These data show an average deviation of a factor $2.1(0.32 \log$ units), and $90 \%$ of reliability 1 versus reliability 2 $\log \mathrm{EC}_{50}$ values fall within a difference of a factor 30 (1.48 log units). Largest deviations in data with different reliability scores per species-substance combination are found for Daphnia magna with $\log \mathrm{EC}_{50}$ varying by more than 5 orders of magnitude (4.1 log units) after exposure to octabenzone (CAS: 1843-05-6) and for Pimephales promelas with log EC50 ${ }_{j}$ varying by up to a factor 8000 (3.9 log units) after exposure to tin (CAS: 7440-31-5). Thereby, no consistent variation in the sensitivity of $\log \mathrm{EC} 50_{j}$ values to reliability scores was observed across test species.

(ii) Comparing different trophic levels: To evaluate our data set with respect to the long-term sensitivity of test species from different trophic levels in the freshwater ecosystem all chronic $\log \mathrm{EC}_{50}$ values per trophic level are plotted in Figure 3 as average per substance 
across all species-specific 'chronic' EC50 data points. Chemicals with data from chronic tests available for only one trophic level are not included.

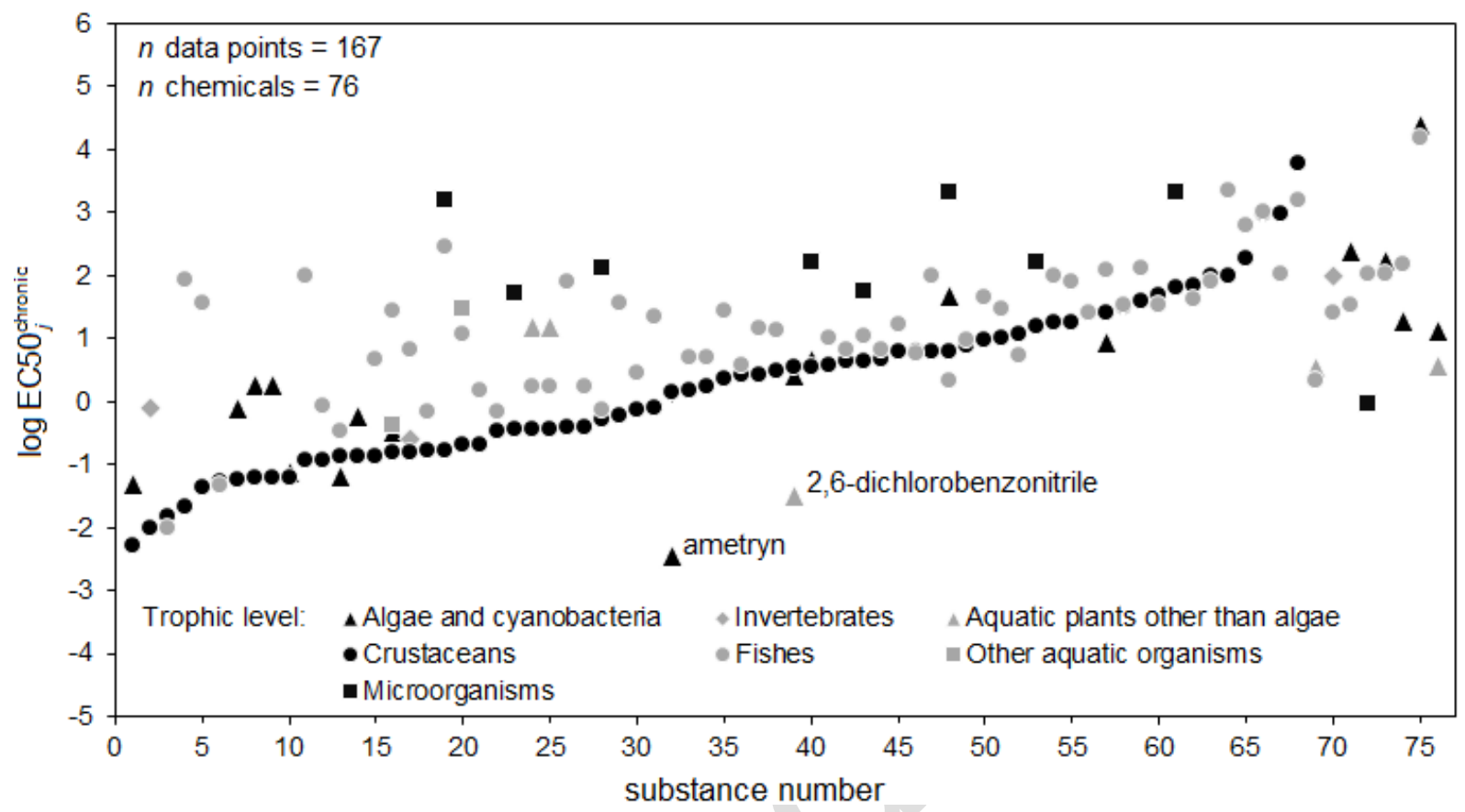

Figure 3. Chronic $\log \mathrm{EC}_{50}(\mathrm{mg} / \mathrm{L})$ values per trophic level, i.e. average values per substance across 'chronic' EC50 data points for all species belonging to that trophic level. Data are ranked according to crustaceans as trophic level with the largest number of data points crustaceans with Daphnia magna as most frequent species and 62 values for fishes, whereas only 3 and 2 values could be calculated for invertebrates and other aquatic organisms, respectively. Figure 3 indicates that species of different trophic levels do not strictly follow the same sensitivity patterns towards chemical exposure. More specifically, crustacean species show consistently a higher sensitivity than fish, algae and other aquatic plants and organisms for exposure to many substances. In contrast, for a limited number of the analyzed substances for which crustacean data exist, other trophic levels are found to be more sensitive, potentially because these substances have specific effect mechanisms towards the species of 
311 these trophic levels (like e.g. herbicides acting on algae and macrophytes). However, there are

312 not enough data points and chemicals included to generalize this deviation from the general

313 trend. Exceptions from this general trend are moreover ametryn (CAS: 834-12-8), to which

314 algae and cyanobacteria on average show a factor 380 higher sensitivity than crustaceans, and

315 dichlorobenzonitrile (CAS: 1194-65-6), to which aquatic plants (other than algae) on average

316 show a factor 100 higher sensitivity than crustacean species. For the different trophic levels,

317 the highest sensitivity is shown for algae and cyanobacteria to ametryn (CAS: 834-12-8) with

318 an average $\log \mathrm{EC}_{50}=-2.4$ (corresponding to an average EC50 $=0.004 \mathrm{mg} / \mathrm{L}$ ), for

319 crustaceans to zinc pyrithione (CAS: 13463-41-7) with an average log EC50 $0_{j}=-2.3$

320 (average EC50 = $0.005 \mathrm{mg} / \mathrm{L}$ ), and for fishes to octamethylcyclotetrasiloxane (CAS: 556-67-

321 2) with an average $\log \mathrm{EC}_{50}=-2$ (average EC50 $\left.=0.01 \mathrm{mg} / \mathrm{L}\right)$, with crustaceans showing

322 a very similar sensitivity to this substance.

Comparing ecotoxicity data from REACH and USEtox

Finally, log HC50 were calculated combining reported chronic data and chronic data

326 estimated from reported acute data with REACH reliability scores 1 and 2 to compare use of ecotoxicity information from REACH with use of data listed in USEtox (Figure 4). Data for organic substances and for cationic metals are taken from USEtox 2.0. 


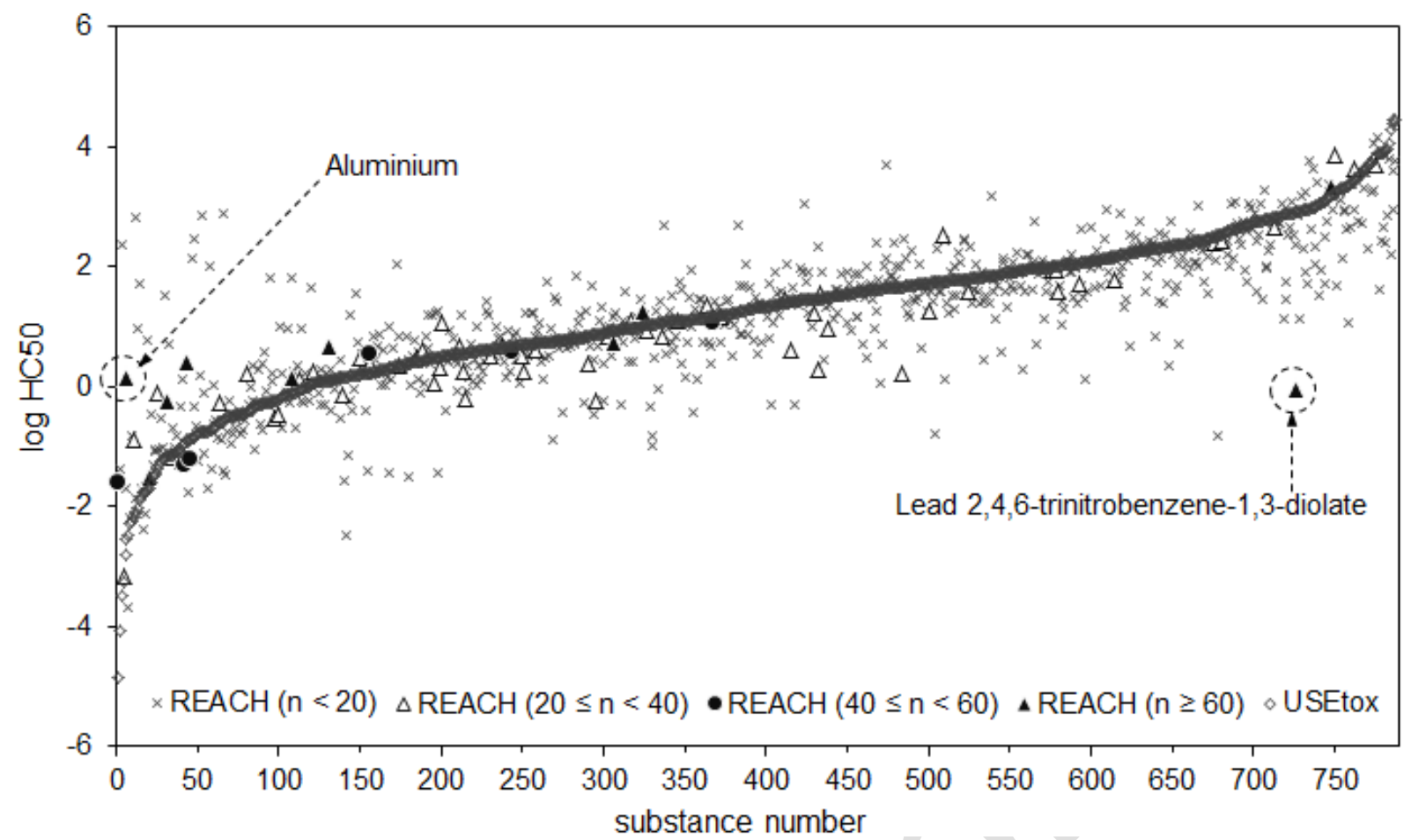

330 Figure 4. Comparison of substance-specific log HC50 values of combined acute and chronic

331 data with reliability scores 1 and 2 from REACH and USEtox. REACH-based values are

332 classified according to the underlying number of reported individual data points per substance

Out of 787 considered substances with ecotoxicity data both in the USEtox database

and in REACH, log HC50 values were calculated from REACH for substances with less than

20 reported data points $(n=714)$, which is considered a desirable minimum for variety in

species and trophic levels with respect to the effect of sample size on accuracy of species

338 distribution models as applied in LCIA [25]. These REACH data deviate from the

339 corresponding log HC50 given in USEtox on average by a factor 2 (0.31 log units) with 95\%

340 of all deviations falling within a factor 44 (1.65 log units). Similarly, log HC50 values

341 calculated from REACH for substances with more than 20 data points $(n=73)$ deviate on

342 average from the corresponding USEtox values by a factor 1.7 (0.23 log units) with $95 \%$ of

343 deviations falling within a factor 23 (1.35 log units). For 30\% of all considered substances

$344(n=237)$ less than 5 data points were available in REACH. In contrast, for 16 substances 
345 more than 40 data points were available in REACH and for 3 cationic metals, namely for

346 aluminium, silver and nickel, more than 100 data points were available. Surprisingly, the

$347 \log \mathrm{HC} 50=0.14$ for aluminium (CAS RN: 7429-90-5) with 107 data points available in

348 REACH, comprising 17 chronic and 90 acute data points representing species from 3 trophic

349 levels, deviates by a factor 500 (2.7 log units) from the $\log$ HC50 $=-2.56$ listed in USEtox

3502.0 based on data also from species from 3 trophic levels provided in Dong et al. (2014) [23].

351 However, both $\log$ HC50 $=0.14$ values fall within the range of sensitivities of species from

352 the different trophic levels covering more than 4 orders of magnitude for this substance

353 (Figure 5A). This indicates that the calculated log HC50 heavily depends on the considered

354 species and trophic levels. A similar deviation is found for exposure to lead 2,4,6-

355 trinitrobenzene-1,3-diolate (CAS RN: 15245-44-0) with 92 evaluable EC50 data points

356 available in REACH. The calculated $\log \mathrm{HC} 50=-0.04$ deviates from the corresponding

357 value in USEtox of $\log \mathrm{HC} 50=2.9$ by a factor 870 (2.95 $\log$ units). The underlying REACH

358 data consist of tests from 3 different trophic levels (Figure 5B), all based on acute tests. The

359 value listed in USEtox is based on a single acute test data point [10] that is not included in

360 REACH. 

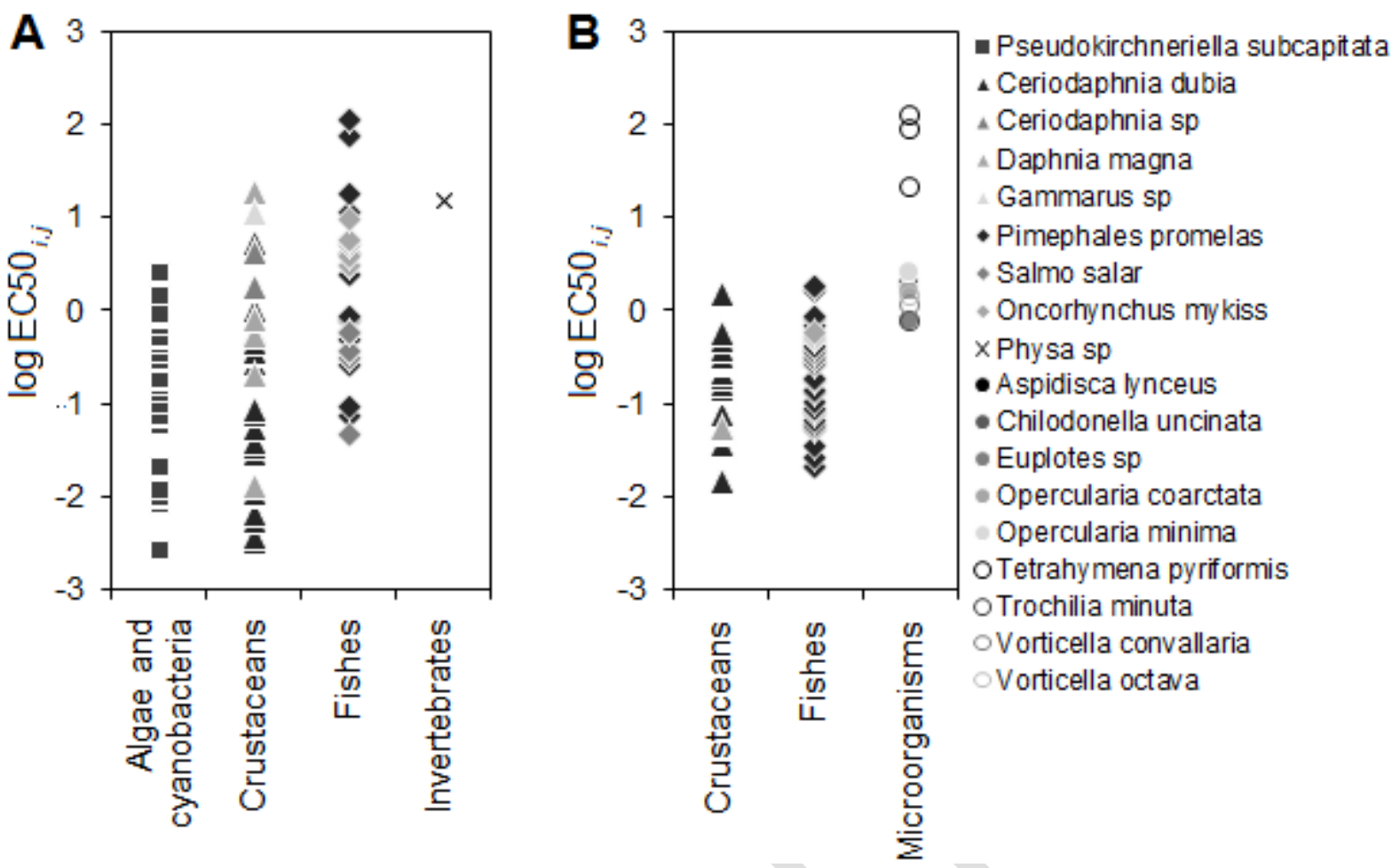

363 Figure 5. Sensitivity distribution of different species within distinct trophic levels to exposure

364 of (A) aluminium and (B) lead 2,4,6-trinitrobenzene-1,3-diolate expressed by individual

365 reported $\log \mathrm{EC}_{50} 0_{i, j}$ acute and chronic data points in $\mathrm{REACH}$

\section{DISCUSSION}

\section{REACH internal data evaluation}

It is a requirement in REACH that tests have to be carried out in compliance with the

370 principles of Good Laboratory Practice (GLP) described in Directive 2004/10/EC [26]. In

371 addition, in Annexes VII to X on standard information requirements, the use of various

372 OECD test guidelines is required in cases where no EU test method exists [14]. Deviations

373 from the standard guidelines need to be explicitly indicated in line with the endpoint-specific

374 testing strategies for aquatic toxicity testing [19] and reflected in the reliability score of the

375 reported data. However, issues in complying with data reporting requirements including

376 reliability have recently been identified in several studies [27-29]. This means for the 
Müller, N., de Zwart, D., Hauschild, M., Kijko, G., \& Fantke, P., 2016. Exploring reach as potential data source for characterizing ecotoxicity in life cycle assessment. Environmental Toxicology and Chemistry, 9999(9999), pp.1-9. DOI: 10.1002/etc.3542.

potential use of REACH data in LCIA that compliance with reporting requirements might need to be double checked.

The average of 9.8 data points available in REACH per substance included in the present study for freshwater ecotoxicological information seems generally sufficient for comparative assessment purposes, but a fraction of only $7.5 \%$ of the data being based on chronic tests demonstrates a strong dependency on predominantly acute test data.

Extrapolation from acute to chronic exposure data remains a topic for future research. This might also include to look at data reported for additional effect endpoints, such as noobserved effect concentrations (NOEC) to increase available data for comparative toxicity characterization [30], although EC50 data are generally considered more suitable for relative comparison applications [31].

Sensitivities to some substances vary strongly between the tested species whether they belong to the same or to different trophic levels. This is the case when the chemical has a specific mode of action towards some species and a perhaps more general narcotic mode of action against all other species. This means that high deviations between the log HC50 values calculated for the same substance from data of different data sources do not necessarily indicate a poor quality of the underlying data of any particular data source. This leads to the conclusion that the quality and representativeness of the calculated log HC50 values from REACH data can be improved by including toxicity test data for as many different species and trophic levels as possible, thereby also exploring additional data sources than those currently included in REACH.

\section{REACH and USEtox data comparison}

Only 5\% of the approximately 15000 substances registered under REACH are included in the present study, i.e. those that also have ecotoxicity effect data listed in USEtox. REACH data that are not associable with a unique substance via a CAS registration number 
Müller, N., de Zwart, D., Hauschild, M., Kijko, G., \& Fantke, P., 2016. Exploring reach as potential data source for characterizing ecotoxicity in life cycle assessment. Environmental Toxicology and Chemistry, 9999(9999), pp.1-9. DOI: 10.1002/etc.3542.

as substance identifier - in our test set of selected substances approximately $50 \%$ of the data are not useful for LCA, where emissions and impacts are calculated at the level of individual substances. The use of relevant data from REACH is further limited by the fact that around $25 \%$ of the data have a reported reliability score higher than 2 (i.e. data not considered reliable) and many reported ecotoxicity data are based on endpoints currently not considered in LCIA - in our test set these together eliminate approximately $53 \%$ of all data points. While we only used the remaining $47 \%$ of data from REACH in our comparison with USEtox to gain deeper insight into data considered reliable and matching effect endpoints currently used in LCIA, the data source situation could be generally improved by further scrutinizing data not considered reliable in REACH and by developing methods to include additional effect endpoints available in REACH.

For USEtox, it is recommended to characterize freshwater aquatic ecotoxicity based on data of at least 3 different species covering at least 3 different trophic levels to ensure a minimum variability of sensitivities towards the substance [5]. Freshwater ecotoxicological effect data are predominantly available for species belonging to algae (phytoplankton; primary producers), crustaceans (zooplankton; primary consumers), fish (secondary/tertiary consumers), and bacteria (microorganisms; reducers) [13]. However, in our test set of considered substances, we found for 181 substances (23\%) that data from only 1 or 2 trophic levels were reported in REACH and for 147 substances (19\%) less than 3 species were reported, while for 606 substances (77\%) data corresponding to the suggested minimum of 3 species from 3 trophic levels were available, and for 39 substances (5\%), even data for 7 or more species from 5 to 7 different trophic levels were available. In contrast, from the ecotoxicity data points listed in USEtox for 2262 organic substances with available information on number of test species and trophic level, for 1659 substances (73\%) data for species from only 1 or 2 trophic levels are listed and for 1187 substances (52\%) less than 3 species are listed, while for 604 substances (27\%) the suggested minimum of at least 3 species 
Müller, N., de Zwart, D., Hauschild, M., Kijko, G., \& Fantke, P., 2016. Exploring reach as potential data source for characterizing ecotoxicity in life cycle assessment. Environmental Toxicology and Chemistry, 9999(9999), pp.1-9. DOI: 10.1002/etc.3542.

from 3 different trophic levels are listed. The problem with this situation is reflected in our results, where the majority of substances for which log HC50 from REACH and USEtox show large deviations of more than a factor 10 typically either has only very few underlying data points in REACH, USEtox, or even both. Consequently, different scrutinized data sources should be consistently combined building a stronger ecotoxicity characterization data basis in order to accommodate the desired stability when using average values across all available data, species and trophic levels for LCIA purposes.

Finally, chronic effect endpoints are strongly suggested as preference over acute endpoints as it has been shown that single-species chronic tests are the most suitable in many cases to reflect whole ecosystem sensitivity to chemical exposure [32].

The assumption of a generic conversion factor from acute to chronic effects currently implemented in USEtox may explain some of the significant differences between log HC50 calculated from REACH versus USEtox. First estimates for cationic metals indicate a high variation in the acute-to-chronic relationship for different trophic levels in tests with the same substance, where it was shown that for aluminium, fishes show in general more than 6 times higher acute-to-chronic ratios than crustaceans [23]. For a wide range of organic substances, however, it was shown that there is no systematic deviation between chronic and acute endpoints for most considered substances [33]. Therefore, we recommend focusing future research efforts on assessing the feasibility of defining acute-to-chronic ratios at the level of test species or trophic levels and chemical classes or toxic mode of action.

\section{Options for improving LCIA ecotoxicity characterization}

$$
\text { Using REACH ecotoxicity information as one potential input data source for }
$$
freshwater ecotoxicity characterization in LCIA requires addressing several aspects. Data from study types such as read-across, QSAR or grouped data should be excluded. Further, data with reported reliability scores other than 1 and 2 in REACH should currently not be 
Müller, N., de Zwart, D., Hauschild, M., Kijko, G., \& Fantke, P., 2016. Exploring reach as potential data source for characterizing ecotoxicity in life cycle assessment. Environmental Toxicology and Chemistry, 9999(9999), pp.1-9. DOI: 10.1002/etc.3542.

considered without further scrutinizing. Activated sludge and other potentially inadequate test 'organisms' should be excluded as long as they do not reflect a species of freshwater aquatic ecosystems. Substances in REACH need to have a CAS number to be considered in LCIA to be able to quantify substance-specific fate, exposure and effect factors as well as to match impact characterization results with chemical-specific emission flows. According to Article 111 of the REACH regulation [14], registration dossiers have to be submitted with a software tool through the ECHA-internal IT system. Nevertheless, information is at times entered in a wrong format, category or not entered at all. In fact, ECHA evaluates the general completeness of the registration documents, whereas any statement about the evaluation of the submitted data by ECHA is not part of the regulation. This does not allow for identifying which submitted data effectively comply with the data reporting requirements [27].

The present study is primarily limited with respect to comparing REACH and USEtox at the level of aggregated log HC50 per substance. It would be more appropriate to compare directly individual EC50 data points from REACH with underlying individual EC50 data points used in USEtox. Since the original EC50 data used to compile HC50 values for USEtox are not freely accessible, the comparison has been performed based on aggregated data. However, we recommend that all underlying data used to compile input and output data from USEtox are available on request via the USEtox team to ensure reproducibility and transparency. We recommend directly comparing EC50 values per species and substance in future research to contrast different data sources. Additionally, we recommend collecting and analyzing data from different existing ecotoxicity databases like REACH, OECD SIDS, and ECOTOX to aim for completeness and identify and avoid potential cross-referencing to the same underlying original studies. 
Müller, N., de Zwart, D., Hauschild, M., Kijko, G., \& Fantke, P., 2016. Exploring reach as potential data source for characterizing ecotoxicity in life cycle assessment. Environmental Toxicology and Chemistry, 9999(9999), pp.1-9. DOI: 10.1002/etc.3542.

Hence, using REACH as a continuously updated and extended data source could be a starting point to improve the current data situation in LCIA with several tens of thousands of available ecotoxicity data for approximately 15000 registered chemicals as of 2015 . To use this potential, however, it is a prerequisite to further assess the reported data in terms of reliability and applicability for LCIA as we found several aspects that require further research before considering REACH as a viable data source in the consensus model USEtox. REACHinternal quality control of approximately $5 \%$ of the submitted data might be sufficient for the actual purpose of this database to support regulatory risk assessment if these $5 \%$ mainly focus on the most sensitive species. For the purpose of being applied in LCIA, however, the most sensitive species is not considered as good a representative of the sensitivity of the exposed ecosystem as the average across all sensitivities of all available (tested) species and trophic levels. When considering all data from REACH that are labeled reliable (with and without restrictions), it would hence be necessary to scrutinize all data (including the $95 \%$ of data that are currently not checked by ECHA). Focus in future research efforts should be put on systematically analyzing differences between data with reliability scores 1 and 2 and between acute and chronic data as these are currently also the main limitations in LCIA models with respect to ecotoxicity characterization. As REACH contains a very limited amount of reported 500 chronic EC50 (or equivalent) data, extrapolations are necessary from acute to chronic effects, which also requires further research and improvement. Finally, it remains unclear how well REACH covers existing and available ecotoxicity data for characterizing ecotoxicity in LCIA.

503 In conclusion, we recommend to systematically investigating quality-, extrapolation-, and 504 applicability-related issues, before considering REACH and also other available databases as 
Müller, N., de Zwart, D., Hauschild, M., Kijko, G., \& Fantke, P., 2016. Exploring reach as potential data source for characterizing ecotoxicity in life cycle assessment. Environmental Toxicology and Chemistry, 9999(9999), pp.1-9. DOI: 10.1002/etc.3542.

505 potential basis for the characterization of ecotoxicity in LCIA. For USEtox as consensus-

506 based model, we recommend to explicitly differentiate between substances with sufficient and

507 reliable ecotoxicity information and substances with insufficient or missing ecotoxicity

508 information to pinpoint current data gaps and to avoid underestimating potential effects from

509 substances with missing or insufficient data.

510

SUPPLEMENTAL DATA

Tables S1-S2. (30 KB XLSX).

513

ACKNOWLEDGEMENT

515

The authors would like to thank M. Margni (École Polytechnique de Montréal) and F.

516 Pedersen (Danish Environmental Protection Agency) for discussions around REACH. The

517 present study was financially supported by the Marie Curie project Quan-Tox (grant

518 agreement no. 631910) funded by the European Commission under the Seventh Framework

519 Programme. 


\section{REFERENCES}

[1] European Chemicals Agency. 2016. Information on Chemicals. http://echa.europa.eu/information-on-chemicals [accessed 2016-May-22].

[2] International Organization for Standardization. 2006. ISO 14040 International Standard. Environmental Management - Life Cycle Assessment - Principles and Framework. Geneva, Switzerland.

[3] Pennington DW, Potting J, Finnveden G, Lindeijer E, Jolliet O, Rydberg T, Rebitzer G. 2004. Life cycle assessment Part 2: Current impact assessment practice. Environ. Int. 30:721-739.

[4] Hauschild MZ, Jolliet O, Huijbregts MAJ. 2011. A bright future for addressing chemical emissions in life cycle assessment. Int. J. Life Cycle Assess. 18:697-700.

[5] Rosenbaum RK, Bachmann TM, Gold LS, Huijbregts MAJ, Jolliet O, Juraske R, Koehler A, Larsen HF, MacLeod M, Margni MD, McKone TE, Payet J, Schuhmacher M, van de Meent D, Hauschild MZ. 2008. USEtox - The UNEP-SETAC toxicity model: Recommended characterisation factors for human toxicity and freshwater ecotoxicity in life cycle impact assessment. Int. J. Life Cycle Assess. 13:532-546.

[6] Hauschild MZ, Huijbregts MAJ, Jolliet O, Macleod M, Margni MD, van de Meent D, Rosenbaum RK, McKone TE. 2008. Building a model based on scientific consensus for life cycle impact assessment of chemicals: The search for harmony and parsimony. Environ. Sci. Technol. 42:7032-7037.

[7] Westh TB, Hauschild MZ, Birkved M, Jørgensen MS, Rosenbaum RK, Fantke P. 2015. The USEtox story: A survey of model developer visions and user requirements. Int. J. Life Cycle Assess. 20:299-310.

[8] Wintersen A, Roelofs W, Posthuma L, de Zwart D. 2002. Realisation of the RIVM EcoTox Database. Verslagen milieukunde 221 / ECO-note 2002/04. National Institute for Public Health and the Environment (RIVM), Nijmegen, the Netherlands.

[9] United States - Environmental Protection Agency. 2001. The ECOTOXicology knowledgebase (ECOTOX). http://cfpub.epa.gov/ecotox/ [accessed 2015 December 15].

[10] International Uniform Chemical Information Database. 2000. Public data on high volume chemicals: Second edition of an extract of data from the international uniform chemical information database on high production volume chemicals (HPVCs), reported by European industry in the frame of the EU existing chemicals risk assessment programme. European Commission.

[11] Payet J. 2004. Assessing toxic impacts on aquatic ecosystems in life cycle assessment (LCA). Doctoral thesis. Ecóle Polytechnique Fédérale de Lausanne, Lausanne, Switzerland.

[12] Henderson AD, Hauschild MZ, van de Meent D, Huijbregts MAJ, Larsen HF, Margni M, McKone TE, Payet J, Rosenbaum RK, Jolliet O. 2011. USEtox fate and ecotoxicity factors for comparative assessment of toxic emissions in life cycle analysis: sensitivity to key chemical properties. Int. J. Life Cycle Assess. 16:701-709. 
[13] Larsen HF, Hauschild M. 2007. GM-troph: A low data demand ecotoxicity effect indicator for use in LCIA. Int. J. Life Cycle Assess. 12:79-91.

[14] European Commission. 2006. Regulation (EC) No 1907/2006 of the European Parliament and of the Council of 18 December 2006 concerning the Registration, Evaluation, Authorisation and Restriction of Chemicals (REACH). Brussels, Belgium.

[15] Askham C. 2012. REACH and LCA - methodological approaches and challenges. Int. J. Life Cycle Assess. 17:43-57.

[16] Igos E, Moeller R, Benetto E, Biwer A, Guiton M, Dieumegard P. 2014. Development of USEtox characterisation factors for dishwasher detergents using data made available under REACH. Chemosphere 100:160-166.

[17] Klimisch H-J, Andreae M, Tillmann U. 1997. A systematic approach for evaluating the quality of experimental toxicological and ecotoxicological data. Regul. Toxicol. Pharm. 25:1-5.

[18] Sobanska MA, Cesnaitis R, Sobanski T, Versonnen B, Bonnomet V, Tarazona JV, De Coen W. 2014. Analysis of the ecotoxicity data submitted within the framework of the REACH Regulation. Part 1. General overview and data availability for the first registration deadline. Sci. Total Environ. 470-471:1225-1232.

[19] European Chemicals Agency. 2014. Guidance on information requirements and chemical safety assessment Chapter R.7b: Endpoint specific guidance. Helsinki, Finland.

[20] Embry ME, Belanger SE, Coady K, de Zwart D, Farr B, Gutsell S, Halder M, Sanderson H, Sternberg R, Wilson P. 2015. Ecotoxicological Threshold of Concern (eco-TTC): Development of an approach to assist in environmental hazard assessment. Society of Environmental Toxicology and Chemistry Europe 25th Annual Meeting, 3-7 May, 2015, Barcelona, Spain.

[21] European Centre for Ecotoxicology and Toxicology of Chemicals. 1993. Aquatic toxicity data evaluation. Technical Report No 56. Brussels, Belgium.

[22] de Zwart D. 2002. Observed regularities in species sensitivity distributions for aquatic species. In Posthuma L, Suter II GW, Traas TP, eds, Species Sensitivity Distributions in Ecotoxicology. CRC Press, Boca Raton, pp 133-154.

[23] Dong Y, Gandhi N, Hauschild MZ. 2014. Development of comparative toxicity potentials of 14 cationic metals in freshwater. Chemosphere 112:26-33.

[24] European Chemicals Agency. 2012. Guidance on registration. Helsinki, Finland.

[25] Stockwell DRB, Peterson AT. 2002. Effects of sample size on accuracy of species distribution models. Ecol. Model. 148:1-13.

[26] European Commission. 2004. Directive 2004/10/EC of the European Parliament and of the Council of 11 February 2004 on the harmonisation of laws, regulations and administrative provisions relating to the application of the principles of good laboratory 
Müller, N., de Zwart, D., Hauschild, M., Kijko, G., \& Fantke, P., 2016. Exploring reach as potential data source for characterizing ecotoxicity in life cycle assessment. Environmental Toxicology and Chemistry, 9999(9999), pp.1-9. DOI: 10.1002/etc.3542.

practice and the verification of their applications for tests on chemical substances. Brussels, Belgium.

[27] German Federal Environment Agency. 2015. REACH Compliance: Data Availibility of REACH Registration. Part 1: Screening of chemicals > 1000 tpa. Dessau-Roßlau, Germany.

603

604

605

606

607

608

609

610

611

612

613

614

615

616

617

618

619

620

621
[28] Austin T, Denoyelle M, Chaudry A, Stradling S, Eadsforth C. 2015. European Chemicals Agency dossier submissions as an experimental data source: Refinement of a fish toxicity model for predicting acute $\mathrm{LC}_{50}$ values. Environ. Toxicol. Chem. 34:369378.

[29] European Environmental Bureau. 2012. Identifying the bottlenecks in REACH implementation: The role of ECHA in REACH's failing implementation. Brussels, Belgium.

[30] Beasley A, Belanger SE, Brill JL, Otter RR. 2015. Evaluation and comparison of the relationship between NOEC and $\mathrm{EC}_{10} / \mathrm{EC}_{20}$ values in chronic Daphnia toxicity testing. Environ. Toxicol. Chem. 34:2378-2384.

[31] Pennington DW, Payet J, Hauschild M. 2004. Aquatic ecotoxicological indicators in life-cycle assessment. Environ. Toxicol. Chem. 23:1796-1807.

[32] Versteeg DJ, Belanger SE, Carr GJ. 1999. Understanding single-species and model ecosystem sensitivity: Data-based comparison. Environ. Toxicol. Chem. 18:1329-1346.

[33] Posthuma L, de Zwart D. 2006. Predicted effects of toxicant mixtures are confirmed by changes in fish species assemblages in Ohio, USA, rivers. Environ. Toxicol. Chem. 25:1094-1105. 